\title{
Optimization Analysis of Dynamic Modal Characteristics of Large Draw Ratio Rocket Body Structure
}

\author{
Hao Wang ${ }^{1, a}$, Longbin Liu $^{1, b, *}$, Weihua Zhang ${ }^{1, c, *}$ \\ ${ }^{1}$ College of Aerospace Science and Engineering, National University of Dgefense Technology, \\ Deja Road, Changsha, China

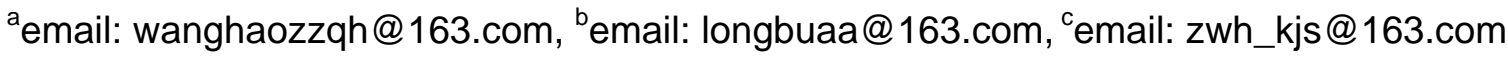 \\ ${ }^{*}$ corresponding author
}

Keywords: large draw ratio rocket, rocket structure, natural frequency, optimization analysis.

\begin{abstract}
With the development of rocket technology, the demand of large draw ratio rocket with big carrying is improved. In this artical, for the purpose of optimization analysis of large draw ratio rocket's dynamic modal characteristics, a finite element model is established firstly. Then the structure of the rocket body is reconstructed and the modal analysis is done with simulation software. Finally, the frequencies of the bending vibration of the structure are obtained by means of finite element analysis. Through the combination with current engineering conditions, the article analyses rationality of the optimization model, which provides an effective method for the optimization of the dynamic modal characteristics of rocket structure.
\end{abstract}

\section{Introduction}

With the development of modern warfare, the demand for the launch speed and power of the rocket weapon is more and more urgent [1]. Compared with original rockets, the long draw ratio has been greatly improved, so various types of rocket projectile with large draw ratio have become a research hotspot [2][3]. The dynamic modal characteristics of large draw ratio rocket at high speeds are very important for stable operation and ballistic performance of the rocket. In early years, rockets' body is assumed to be a rigid body [4][5]. In fact, a rocket's body is an elastic body which has the problem of unstable motion state caused by sloshing of liquid fuel in propellant tank. There are a number of low frequency vibration sources in rocket structure, such as the liquid sloshing in storage tank and Components' vibration [6]. The low frequency vibration sources in the rocket, the rocket body and control system are easy to set up resonance during flight[7]. It will seriously affect the normal work of rocket power system and control system, and even lead to loss of control in flight.

To solve this problem, this article analyses dynamic modal of large draw ratio rockets to avoid the resonance phenomenon from low-frequency vibration sources, puts forward several solutions to change the inherent frequency of rocket body structure and analyses the rationality and feasibility of each scheme[8][9]. In the course of the study on the dynamic characteristics of projectile, the rocket body is simplified as a beam. Although this method is of low accuracy, it can be used to optimize the natural frequency of the structure.

\section{Finite Element Modal Analysis}

Modal analysis is used to determine the vibration characteristics of the structure, including the natural frequencies and modes of vibration which is important parameters in the design of dynamic load structure. In this article, the finite element method is used to discretize the elastic structure into a certain number of units with the mass and elastic characteristics firstly[10]. Because of the small size of elements, it is reasonable to make some assumptions about laws of displacement. Secondly, The method avoids the difficulty of solving differential equations in elastic mechanics through simplified assumption, so that the problem of an infinite degree of freedom becomes a discrete system with finite degrees of freedom. Thirdly, using simulation software, the natural frequency is 
obtained by numerical simulation.

In the case of no damping, dynamic problems can be simplified to solving a system of linear ordinary differential equations:

$[M]\{\ddot{U}\}+[K]\{U\}=\{F\}$

This is a typical undamped modal analysis, which belongs to classical eigenvalue problems:

$$
[K]\left\{\Phi_{i}\right\}=\omega_{i}^{2}[M]\left\{\Phi_{i}\right\}
$$

Where:

$[K]$ : System stiffness matrix;

$\left\{\Phi_{i}\right\}$ : Modal vector of order ${ }^{\mathrm{i}}$;

$\omega_{\mathrm{i}}$ : The natural frequency of the ${ }^{\mathrm{i}}$ order mode ( $\omega_{i}^{2}$ is the eigenvalue);

$[M]$ : System mass matrix;

$\{U\}$ : Unknown generalized coordinate vector of system;

$\{\ddot{U}\}$ : The two order derivative vector of generalized coordinates to time;

$\{F\}$ : System generalized force vector.

For beams with constant properties and frameworks composed of such structures, it is assumed that the main physical properties of it are flexural stiffness EI (x) and per unit length's mass m(x) which can vary arbitrarily with the position $\mathrm{x}$. We consider a motion equation of a basic situation, undamped free vibration:

$$
E I \frac{\partial^{4} v(\mathrm{x}, \mathrm{t})}{\partial x^{4}}+\bar{m} \frac{\partial^{2} v(\mathrm{x}, \mathrm{t})}{\partial t^{2}}=0
$$

Then the shape function $\phi(\mathrm{x})$ can be derived, and the complete solution is as follows:

$$
\phi(x)=G_{1} \exp (\text { iax })+G_{2} \exp (- \text { iax })+G_{3} \exp (a x)+G_{4} \exp (-a x)
$$

The $G_{i}$ in the formula must be treated as a complex constant. The exponential function is replaced by trigonometric function and hyperbolic function, and the imaginary part is zero. The following can be deduced:

$$
\phi(\mathrm{x})=A_{1} \cos a x+A_{2} \sin a x+A_{3} \cosh a x+A_{4} \sinh a x
$$

Where $A_{i}$ are real constants which can be represented by $G_{i}$. The four real constants are calculated from the known boundary conditions ( including the displacement, slope, bending moment and shear).

The rocket body material is set to aluminum alloy 6061, and the related parameters are shown in Table 1.

Table 1 Material parameters of rocket body structure.

\begin{tabular}{|l|l|l|l|}
\hline Ultimate tensile strength & $124 \mathrm{MPA}$ & Ultimate bending strength & $228 \mathrm{MPa}$ \\
\hline Tensile yield strength & $55.2 \mathrm{MPa}$ & Poisson ratio & 0.330 \\
\hline extensibility & $25.0 \%$ & fatigue strength & $62.1 \mathrm{MPa} 0$ \\
\hline Elastic coefficient & $68.9 \mathrm{GPa}$ & density & $2800 \mathrm{~kg} / \mathrm{m}^{3}$ \\
\hline
\end{tabular}

The Rocket need to be optimized have a large draw ratio and complex structure, so in the finite element analysis, the structure will be simplified reasonably. Simplifying the structure of the rocket into a $30 \mathrm{~m}$ beam, its section is a solid circle of radius $0.255 \mathrm{~m}$. The first order bending natural frequency is $2.5027 \mathrm{~Hz}$, in order to increase the natural frequency of the first order bending to $3.5 \mathrm{~Hz}$, this article analyzes the advantages and disadvantages of various optimization schemes.

In finite element analysis, the structure is divided into 30 parts, and unconstrained state simulation of free flight has been down. 

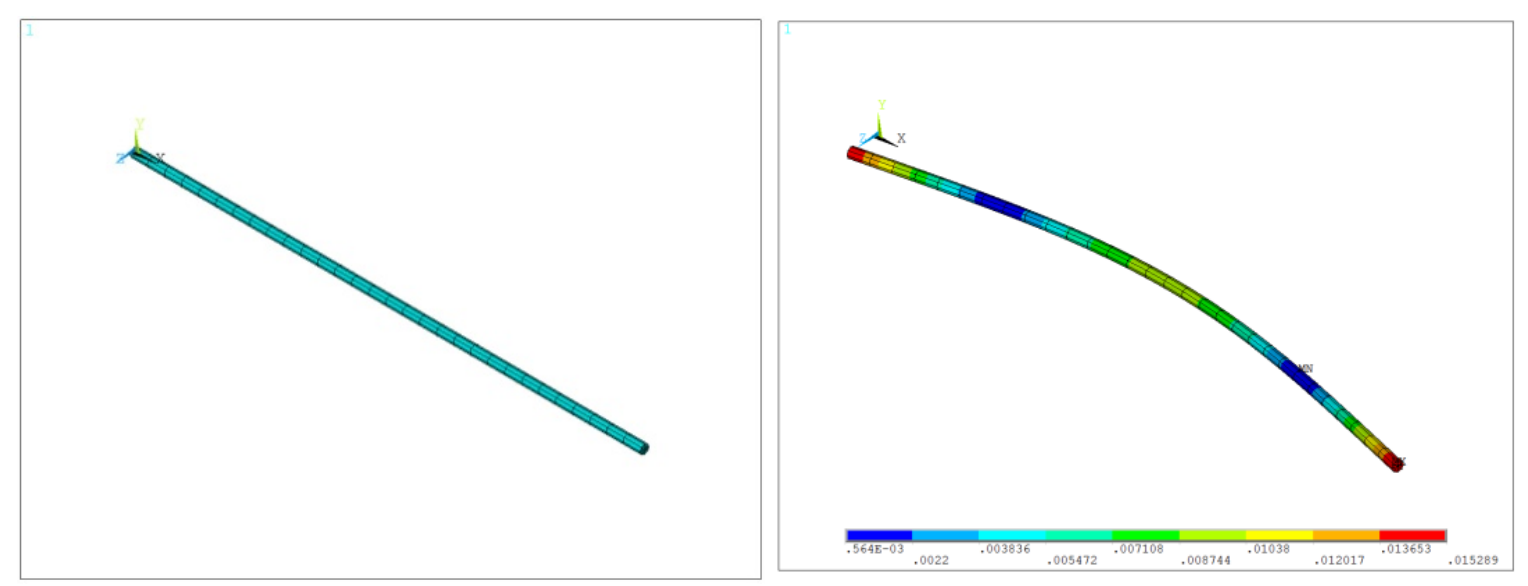

Figure 1 The mesh of rocket structure and the first order vibration mode before optimization.

\section{Optimization of The Rocket Structure and Dynamic Modal Analysis Results}

Taking into account several methods that can change the natural frequency of the first order bending vibration of the rocket body structure, this article mainly analyzes schemes from three aspects:

1) change the size of the rocket body's section, that is, by changing the thickness of the rocket body to achieve the frequency require;

2) change the rocket body's section from solid circle to concentric circles;

3) the rocket body is divided into several parts for different processing that the outer layer of the middle part is coated with a metal layer so that the section of middle part is enlarged, and the part of the end of the rocket is perforated at the same time;

4) add mass points in different locations.

These designs are carried out under original rocket body section of solid circle conditions. The simulation software is used to design the parameters of different sections, and the optimal design scheme which meet the condition of frequency is obtained.

\subsection{Change the Section Size of The Rocket}

The initial section of the rocket body is a solid circle of radius $0.255 \mathrm{~m}$, and the radius of the circular section is gradually increased to get the natural frequency of the first order bending which is shown in table 2:

Table 2 The variation of the natural frequency with the radius of the section circle.

\begin{tabular}{|c|c|c|c|c|c|c|c|c|c|}
\hline Circle radius(m) & 0.255 & 0.26 & 0.28 & 0.3 & 0.32 & 0.34 & 0.35 & 0.355 & 0.357 \\
\hline $\begin{array}{c}\text { First order natural } \\
\text { frequency(Hz) }\end{array}$ & 2.5027 & 2.5517 & 2.7092 & 2.9023 & 3.0954 & 3.2883 & 3.4328 & 3.4816 & 3.5012 \\
\hline
\end{tabular}

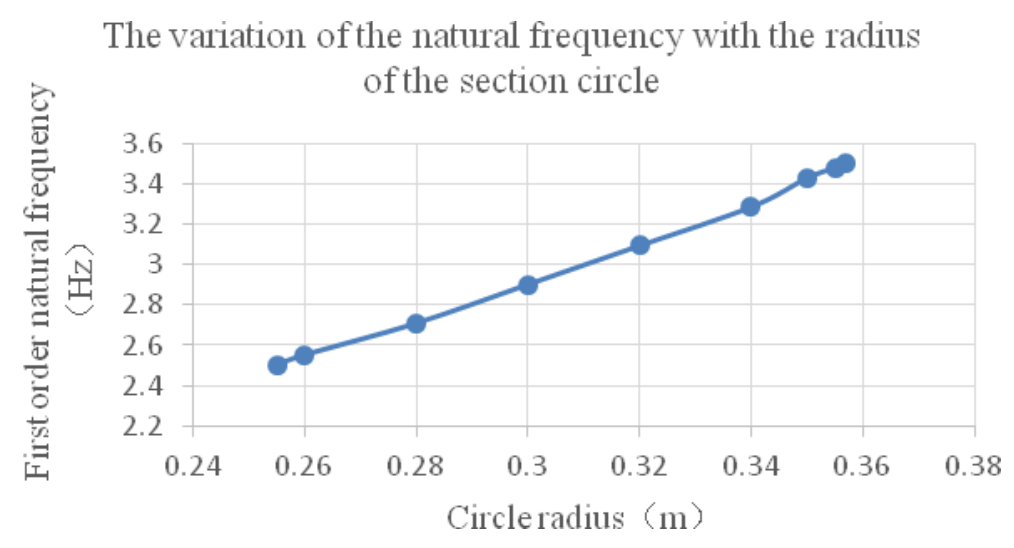

Figure 2 The variation of the natural frequency with the radius of the section circle. 
It can be concluded that if welding a sheet of aluminum alloy material on outer layer of the rocket, the additional plate thickness required is $10.2 \mathrm{~cm}$. This method needs too much aluminum alloy materials, while bringing a greater weight burden to the rocket and resulting in high cost and superior difficulty.

\subsection{Change The Section Shape of The Rocket}

Change the rocket body's section from solid circle to concentric circles. Increasing the radius of the middle air hole, the natural frequency of the first order bending is shown in the following table:

Table 3 The variation of the natural frequency with the air hole radius in the section

\begin{tabular}{|l|l|l|l|l|l|}
\hline air hole radius $(\mathrm{m})$ & 0.18 & 0.20 & 0.23 & 0.245 & 0.25 \\
\hline First order natural frequency $(\mathrm{Hz})$ & 3.0610 & 3.1777 & 3.3665 & 3.4663 & 3.5003 \\
\hline
\end{tabular}

According to the parameters of the dynamic modal characteristics, the natural frequency increases with the increasing of the middle hole's radius. When the radius of the middle hole reaches $0.25 \mathrm{~m}$, it can meet the requirement of $3.5 \mathrm{~Hz}$. In this way two concentric circle radius difference is only $0.5 \mathrm{~cm}$. Compared with the body length of $30 \mathrm{~m}$, the size is too small, while the structural strength of body can not meet the actual needs. So this optimization scheme is not reasonable.

\subsection{Segmental Optimization to The Rocket}

First of all, the rocket is divided into three parts. The middle section is welded a layer of $4.5 \mathrm{~cm}$ aluminum alloy plate so that the circle radius of the middle section becomes $0.3 \mathrm{~m}$ and the first order bending natural frequency increases to $2.9647 \mathrm{~Hz}$. When the welded aluminum alloy plate's thickness of middle section is increased to $9.5 \mathrm{~cm}$, the circle radius of the middle section becomes $0.35 \mathrm{~m}$. At the same time the first order bending natural frequency is changed to $3.2990 \mathrm{~Hz}$.

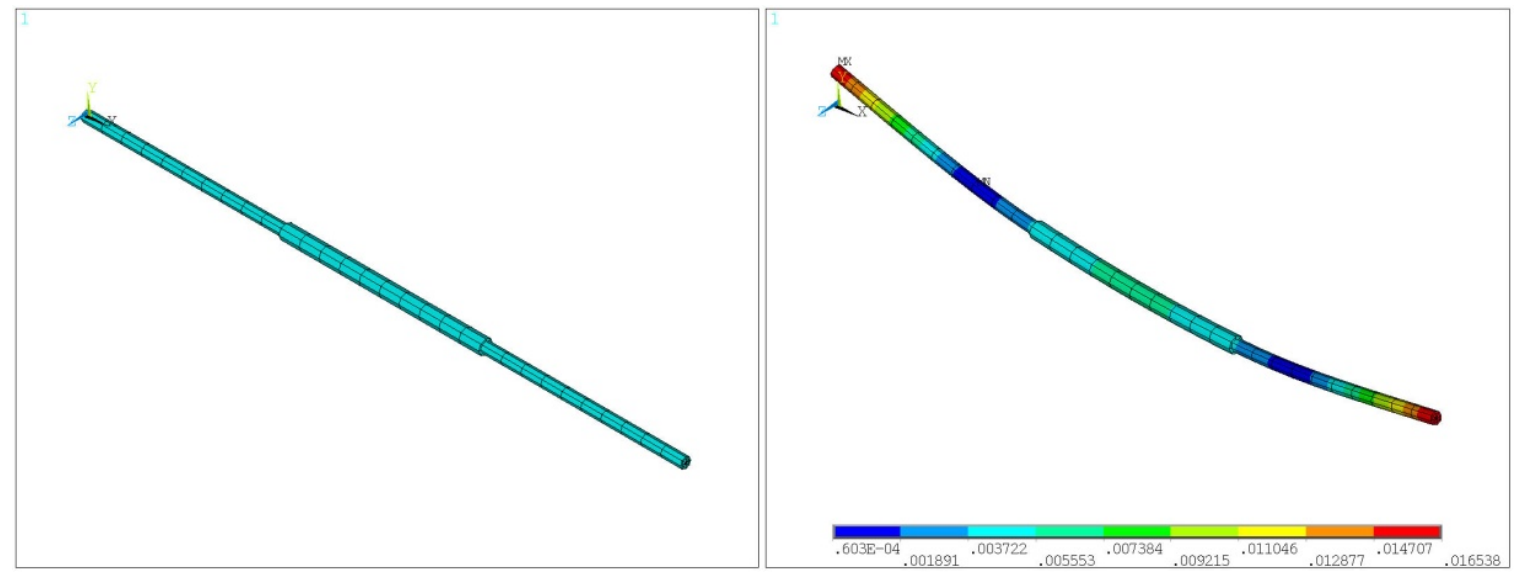

Figure 3 The mesh of rocket structure and the first order vibration mode in three segments optimization scheme.

Then, the rocket is divided into four parts, the middle two sections are welded a layer of $4.5 \mathrm{~cm}$ aluminum alloy plate so that the first order bending natural frequency increased to $3.1498 \mathrm{~Hz}$. When the welded aluminum alloy plate's thickness of two middle sections is increased to $9.5 \mathrm{~cm}$, the first order bending natural frequency is changed to $3.8260 \mathrm{~Hz}$ at the same time.

Comparing two methods above of rocket body division, it can be concluded that four segments optimization scheme which can achieve better effect of increasing the natural frequency of the rocket is more feasible.

When the rocket is divided into four parts, additional plates need to be increased to $7.5 \mathrm{~cm}$ so that the first order bending natural frequency can meet requirements. So combine two methods that the sections of the two middle parts are enlarged and the parts of the ends of the rocket are perforated.

Through the continuous modification and calculation to design data, a more reasonable optimization scheme is obtained. That is dividing the rocket which the radius of solid circle section is $0.255 \mathrm{~m}$ into four parts. The middle two sections are welded a layer of $1 \mathrm{~cm}$ aluminum alloy plate, so that the circle radius of the middle section becomes $0.265 \mathrm{~m}$. Next, the sections of the ends of the rocket are perforated so that the radius of the middle air hole reaches $0.2 \mathrm{~m}$. Finally, The first order 
natural frequency of bending changes from $2.5027 \mathrm{~Hz}$ to $3.5402 \mathrm{~Hz}$. This optimization scheme use of least additional materials and is easy to meet the strength requirements of the rocket. So it is more reasonable and feasible.

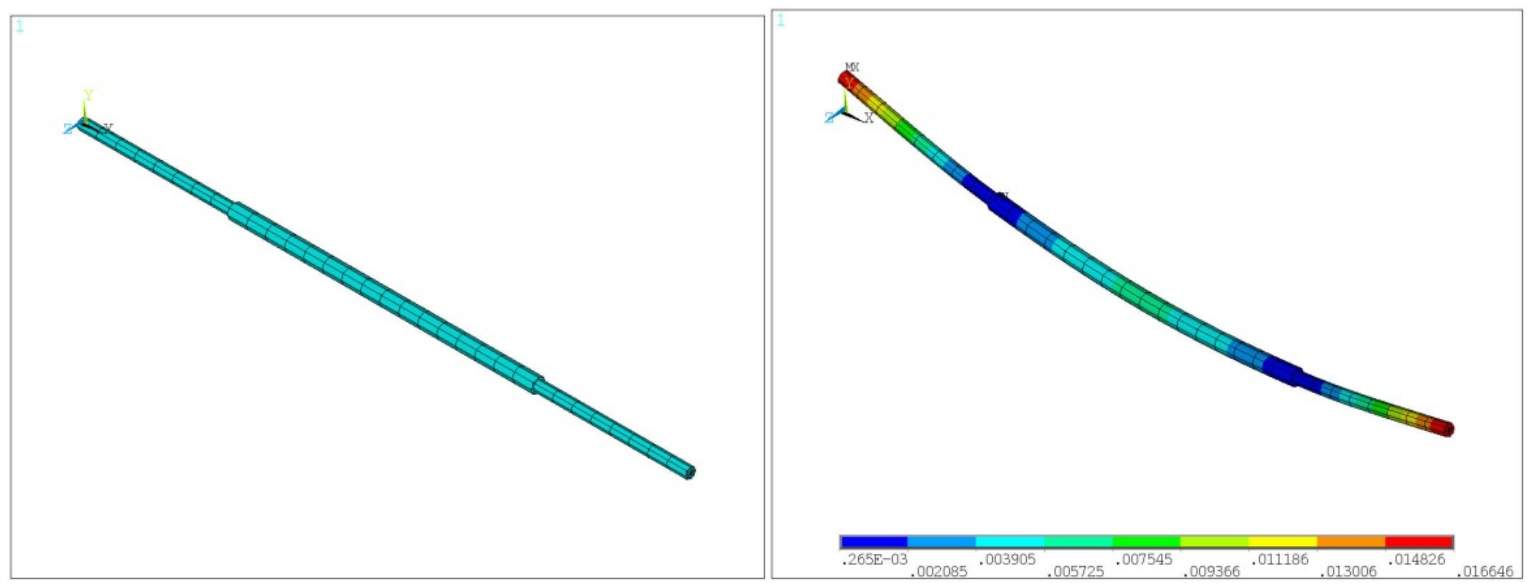

Figure 4 The mesh of rocket structure and the first order vibration mode in four segments optimization scheme.

Table 4 Effect of each optimization program.

\begin{tabular}{|l|l|c|c|c|c|c|}
\hline & \multicolumn{4}{|l|}{$\begin{array}{l}\text { three } \\
\text { optimization scheme }\end{array}$} & \multicolumn{4}{|l|}{ segments segments optimization scheme } \\
\hline The radius of middle section(m) & 0.3000 & 0.3500 & 0.3000 & 0.3250 & 0.3500 & 0.2650 \\
\hline The radius of the end parts' air hole $(\mathrm{m})$ & 0.0000 & 0.0000 & 0.0000 & 0.0000 & 0.0000 & 0.2000 \\
\hline First order natural frequency(Hz) & 2.9647 & 3.2990 & 3.1498 & 3.5000 & 3.8260 & 3.5402 \\
\hline
\end{tabular}

\subsection{Add Mass Points}

Divide the rocket body into four parts. Then difine and number five nodes and Try to add different quality points at different nodes.

Through analysing of dynamic modal parameters and calculating the frequency, a conclusion can be drawn that the natural frequency of the first order bending will decrease no matter where the quality points are placed. So this method is not feasible.

\section{Conclusion}

With the finite element method, the dynamic characteristics of the structure can be obtained. Optimization efficiency of the structure is improved and related costs are effectively reduced in this way.

By contrast, the four segments optimization scheme that each section has different treatment is the most reasonable and feasible scheme. That is dividing the rocket which the radius of solid circle section is $0.255 \mathrm{~m}$ into four parts, then the middle two sections are welded a layer of $1 \mathrm{~cm}$ aluminum alloy plate, so that the circle radius of the middle section becomes $0.265 \mathrm{~m}$. Next, the sections of the ends of the rocket are perforated so that the radius of the middle air hole reaches $0.2 \mathrm{~m}$. Finally, The first order natural frequency of bending changes from $2.5027 \mathrm{~Hz}$ to $3.5402 \mathrm{~Hz}$ to avoid resonance of low frequency vibration sources and losing control of control system.

\section{Acknowledgement}

In this paper, the research was sponsored by the Research project of National University of Defense Technology (Project No. ZK16-03-33).

\section{References}

[1] Tian, X.L., Chen, G.G., (2001) Analysis of Dynamic Characteristics of High Speed and Large 
Aspect Ratio Rocket. Journal of North University of China(Natural Science Edition), 22(6), 400-402.

[2] Yang, G.L. (2013) The In fluence of Flexible Deformation to Large Fineness Ratio Rockets' Aerodynamic Characteristics. Journal of Projectiles, Rockets, Missiles and Guidance, 33(6), 110-113.

[3] Guo, X., Zhang, H.Z., Cheng, X.Y. (2016) Study on dynamic characteristics of high speed and large aspect ratio transmission rod. Aeroengine, 42(3), 28-32.

[4] Zhao, F.T. (2000) An improved initial parameter method for calculating the bending deformation of variable cross-section bar. Journal of Liaoning Provincial College of Communications, 23(1), 55-57.

[5] Li, C.M. (2009) Limit Plane Swing Motion and Its Restraining Measure of Un-rotary Long-range Missile with Large Ratio of Length to Diameter. Journal of System Simulation, 21(23), 7390-7392.

[6] Zhang C., Wei, L.N. (2014) Finite Element Modeling for Large and Complex Aircraft Structure. Machinery Design \& Manufacture.

[7] Yang, L., Wanyan, Z.H. (2016) Design and Implementation of Launch Vehicle’s Structural Dynamic Characteristics Analysis Tool. Computer Measurement \& Control, 6 (24).

[8] Tian, X.L., Chen, G.G. (2001) The Dynamic Characteristics Analysis of High Speed Slender Rocket. Journal of North China Institute of Technology, 6 (22).

[9] Meirovitch, L., Wesley, D.A. (2012) On the dynamic characteristics of a variable- mass slender elastic body under high accelerations. Aiaa Journal, 5(8), 1439-1447.

[10] Shen, J.Y., Mcginley W.M. (2015) Dynamic Analysis of a High Speed Transport Model by Using a Piecewise Continuous Timoshenko Beam Model. Engineering, Construction, \& Operations in Space IV, 27-36. 